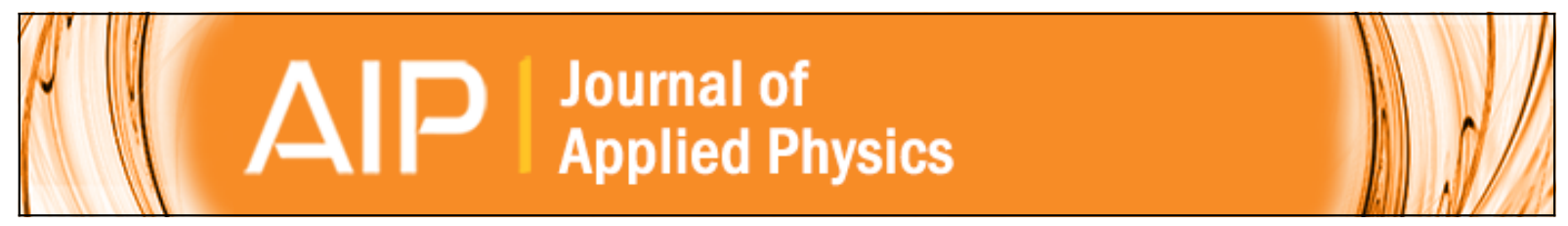

\title{
Effect of Mg doping on dielectric properties of alumina
}

J. Mollá, R. Moreno, and A. Ibarra

Citation: Journal of Applied Physics 80, 1028 (1996); doi: 10.1063/1.362836

View online: http://dx.doi.org/10.1063/1.362836

View Table of Contents: http://scitation.aip.org/content/aip/journal/jap/80/2?ver=pdfcov

Published by the AIP Publishing

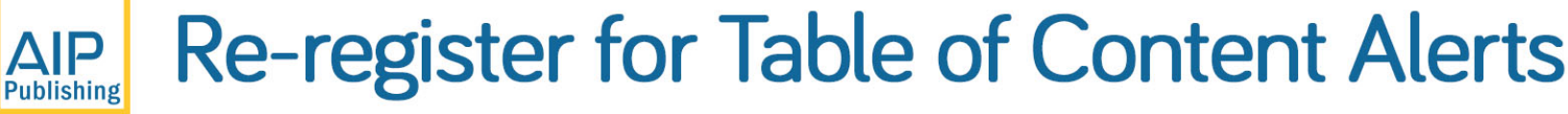

\section{Create a profile. \\ Sign up today!}




\title{
Effect of Mg doping on dielectric properties of alumina
}

\author{
J. Mollá \\ Asociacion Euratom-CIEMAT para Fusión, Av. Complutense 22, E-28040 Madrid, Spain \\ R. Moreno \\ Instituto de Cerámica y Vidrio del CSIC, E-28500 Arganda del Rey, Madrid, Spain
}

A. Ibarra ${ }^{a)}$

Asociacion Euratom-CIEMAT para Fusión, Av. Complutense 22, E-28040 Madrid, Spain

(Received 20 February 1996; accepted for publication 15 April 1996)

\begin{abstract}
Alumina samples with different magnesia concentrations between 0.02 and $1 \mathrm{wt} \%$ have been sintered and characterized by electron microscopy. Their dielectric properties between $1 \mathrm{kHz}$ and 15 $\mathrm{GHz}$ are studied. Different dielectric behaviors are found for different magnesia concentrations. A model based mainly on dipolar relaxation processes is proposed to explain the results obtained. The effect of magnesia on dielectric properties of alumina shown in the present work should be considered in the engineering designs for heating systems of future fusion machines and other applications. (C) 1996 American Institute of Physics. [S0021-8979(96)07214-3]
\end{abstract}

\section{INTRODUCTION}

One of the many problems to be solved before the construction of future fusion machines such as the next european torus (NET) or the international thermonuclear experimental reactor (ITER) is the radio frequency (rf) window for the heating systems. These windows, acting as vacuum and tritium barrier, should be able to transmit high power $(\sim 1$ MW) of radio frequency in three different frequency ranges: approximately $10-80 \mathrm{MHz}$ for ion cyclotron heating, 1-5 $\mathrm{GHz}$ for lower hybrid heating, and $150-200 \mathrm{GHz}$ for electron cyclotron heating. The absorption of a small fraction of the transmitted power will produce high-temperature gradients with the risk of breaking the material due to mechanical stress. The important material parameters to be considered in this framework are complex permittivity together with thermal conductivity and mechanical properties. In this context, although other materials are under consideration, aluminum oxide is being taken as first-choice material in present engineering design studies.

It has been demonstrated that in high-purity sapphire the only dielectric loss over a wide frequency range comes from the interaction of electromagnetic fields with crystal lattice vibrations, producing very low loss tangent at microwave frequencies. ${ }^{1,2}$ However, the presence of impurities gives rise to relaxation processes in the $\mathrm{MHz}$ region and therefore to higher levels of loss tangent which dominate the dielectric loss even at microwave frequencies. ${ }^{1}$ It is not easy to correlate the type of impurities with the different peaks that appear in the loss tangent versus frequency curves, but it is known that $\mathrm{Mg}$ is a common impurity in $\mathrm{Al}_{2} \mathrm{O}_{3}$ and hence one of the candidates responsible for such peaks. In fact, a clear effect of $\mathrm{Mg}$ on the loss tangent of alumina at $20 \mathrm{GHz}$ has been observed. ${ }^{3}$ This effect could be of technological importance for $\mathrm{rf}$ windows in fusion machines since highenergy neutrons coming from the plasma will produce $\mathrm{Mg}$ impurities in $\mathrm{Al}_{2} \mathrm{O}_{3}$ as a result of nuclear transmutation reactions. ${ }^{4}$

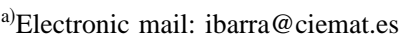

An additional aspect of the problem is the fact $\mathrm{Mg}$ is frequently used as a sintering aid in alumina fabrication since it produces an inhibition of the grain growth as well as an increase in the final density of the material. ${ }^{5-7}$ It is likely that this produces a consequent effect on the dielectric behavior, ${ }^{3}$ however this point has hardly been studied. The present work has been carried out in order to study this problem. The data obtained are also of interest for microwave sintering in which the rate of heating of the material is a function of its loss tangent.

\section{SAMPLE SINTERING AND CHARACTERIZATION}

To carry out this work a set of alumina ceramics were sintered using a high-purity starting powder doped with different concentrations of $\mathrm{MgO}$. The reference alumina powder is the Condea HPA-0.5 (Condea, Germany) and its main characteristics are summarized in Table I. The same powder was doped with concentrations of $0.05,0.1,0.2$, and $1.0 \mathrm{wt} \%$ $\mathrm{MgO}$. Green compacts from pure and doped powders were obtained by wet bag isostatic pressing at $207 \mathrm{MPa}(30000$ psi) and sintered in an electric furnace at $1550{ }^{\circ} \mathrm{C}$ for $1.5 \mathrm{~h}$. These conditions were selected from results obtained previously. ${ }^{3}$ Disks of $30 \mathrm{~mm}$ diameter and $3 \mathrm{~mm}$ thick were cut from sintered plates. The final densities were measured by the immersion method. The microstructure of the sintered samples was observed by scanning electron microscopy (SEM) on polished and thermally etched surfaces. Grain size distributions were evaluated from SEM micrographs by using an image analyzer. The spherical equivalent diameter was evaluated considering that the area enclosed by the closed boundary of a grain is equal to that of a sphere. At least 150 grains per sample were measured.

In Table II the main characteristics of the sintered samples can be found. It is interesting to point out that the addition of small quantities of $\mathrm{MgO}$ in the starting powder produces a density increment which decreases with further $\mathrm{MgO}$ additions. A similar effect was observed by Harmer and Brook $^{6}$ who measured the densification rate of alumina as a function of $\mathrm{MgO}$ concentration and found an increase up 
TABLE I. Main characteristics of the reference alumina powder used.

\begin{tabular}{lcc}
\hline \hline & & Condea-HPA-0.5 \\
\hline Chemical analysis $(\mathrm{ppm}):$ & $\mathrm{SiO}_{2}$ & 60 \\
& $\mathrm{Fe}_{2} \mathrm{O}_{3}$ & 20 \\
& $\mathrm{CaO}$ & 20 \\
& $\mathrm{MgO}$ & 20 \\
& $\mathrm{Na}_{2} \mathrm{O}$ & 40 \\
& $\mathrm{Al}_{2} \mathrm{O}_{3}$ & $99.97 \%$ \\
Specific surface area $\left(\mathrm{m}^{2} / \mathrm{g}\right)$ & & 10 \\
Mean particle size $(\mu \mathrm{m})$ & & 0.5 \\
\hline \hline
\end{tabular}

to $400 \mathrm{ppm}$, which is considered the solubility limit at the sintering temperature. The decreasing density observed for higher $\mathrm{MgO}$ concentrations has not been previously reported, although a dehyphendensification effect was observed by Bennison and Harmer ${ }^{8}$ under some conditions for alumina doped with $\mathrm{MgO}$ at low concentrations.

In addition a trend in the effect of $\mathrm{MgO}$ addition on the average grain size is also observed. Small additions of $\mathrm{MgO}$ tend to reduce the average grain size, and a further addition produces a slight increase. When a very high concentration of $\mathrm{MgO}$ is added, such as $1.0 \mathrm{wt} \%$, the average size decreases due to the formation of a significant concentration of small spinel precipitates. This behavior is in agreement with the results obtained by Bennison and Harmer. ${ }^{7}$ Figure 1 shows the microstructure of the undoped $\mathrm{Al}_{2} \mathrm{O}_{3}$ material and samples doped with $0.1,0.2$, and $1.0 \mathrm{wt} \% \mathrm{MgO}$. For concentrations of $0.1 \mathrm{wt} \%$ some isolated precipitation appears, but is difficult to detect. Higher concentrations of $\mathrm{MgO}$ produce an increased number of spinel precipitates. For $1.0 \mathrm{wt} \%$ many zones with spinel grains can be detected, with a relatively high concentration in some areas. These results are in agreement with those obtained by Johnson and Stein. ${ }^{9}$

\section{EXPERIMENTAL TECHNIQUES}

The dielectric properties of sintered samples were measured at room temperature from $1 \mathrm{kHz}$ to $15 \mathrm{GHz}$. In the frequency range from $1 \mathrm{kHz}$ to $100 \mathrm{MHz}$ the half-power-gap variation method is used. This method is based on a resonant technique in which the response of a resonant circuit is measured when the sample is in between the parallel plates of a condenser and compared with the same measurement without the sample. ${ }^{10}$ The measurements are made using a commercial system from Japan-E\&M (model DPMS-1000). This system allows one to measure loss tangent values higher than $3 \times 10^{-6}$ with a precision better than $\pm\left(3 \times 10^{-6}+0.5 \%\right)$ and permittivity to better than $5 \%$. The precision in absolute per-

TABLE II. Main characteristics of the sintered samples.

\begin{tabular}{llccc}
\hline \hline \multicolumn{1}{c}{ Sample } & $\% \mathrm{MgO}$ & $\begin{array}{c}\text { Density } \\
\left(\mathrm{g} \mathrm{cm}^{-3}\right)\end{array}$ & $\begin{array}{c}\text { Mean grain size } \\
(\mu \mathrm{m})\end{array}$ & $\begin{array}{c}\text { Permittivity } \\
(15 \mathrm{GHz})\end{array}$ \\
\hline $\mathrm{A} / \mathrm{Mg}-0$ & 0.002 & 3.94 & 2.20 & 9.99 \\
$\mathrm{~A} / \mathrm{Mg}-0.05$ & 0.05 & 3.95 & 1.90 & 10.01 \\
$\mathrm{~A} / \mathrm{Mg}-0.1$ & 0.1 & 3.95 & 1.92 & 10.04 \\
$\mathrm{~A} / \mathrm{Mg}-0.2$ & 0.2 & 3.93 & 2.02 & 10.02 \\
$\mathrm{~A} / \mathrm{Mg}-1$ & 1 & 3.90 & 1.85 & 9.93 \\
\hline \hline
\end{tabular}
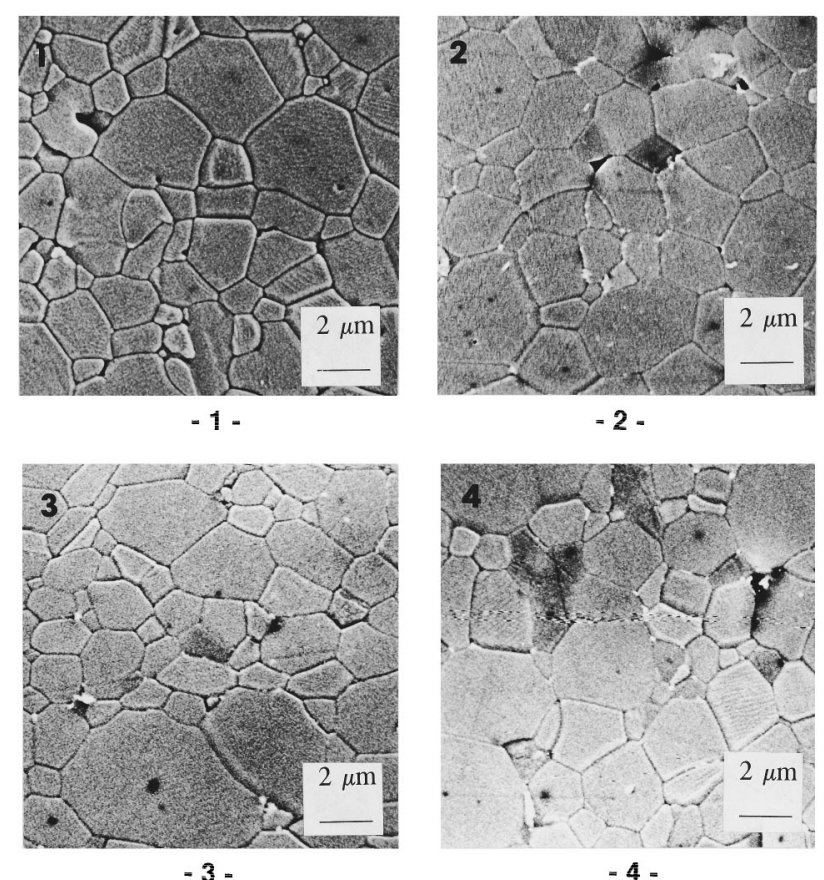

FIG. 1. Microstructure of the samples used in this work. A/Mg-0 (1), A/Mg0.1 (2), A/Mg-0.2 (3), A/Mg-1 (4).

mittivity is limited by the precision in the sample thickness. Better resolution is achieved in the measurement of permittivity with frequency where changes as low as $0.3 \%$ can be measured.

The measurements of dielectric properties at $15 \mathrm{GHz}$ are also based on resonant methods, using closed cylindrical resonant cavities. The dielectric properties are obtained from the comparison of the characteristics of the resonance with and without the sample inside the resonator. This system allows the determination, under optimum conditions, of the permittivity with an error less than $0.1 \%$ and the loss tangent with an error less than $10 \%$ down to values of about $10^{-5}$. Some data at a frequency around $1 \mathrm{GHz}$ are also obtained by a similar measuring technique but using a reentrant cavity instead of a closed cylindrical one.

At high frequency $(15 \mathrm{GHz})$ it is also possible to measure the temperature dependence of dielectric properties. These data are obtained by installing the cavity inside a cryostat, and the data are taken during the free heating of the system. The attainable sensitivity for changes in the permittivity and loss tangent is at least an order of magnitude higher than that for absolute values at room temperature. The measurements are made in a nitrogen atmosphere. Further details may be found in Ref. 11 .

\section{EXPERIMENTAL RESULTS AND DISCUSSION}

The loss tangent results at room temperature for the complete set of samples in the above-mentioned frequency range are represented in Fig. 2. The first point to notice is the large difference in the dielectric behavior of very similar samples, where loss tangent values from $10^{-5}$ to greater than $10^{-3}$ are observed. The sample $\mathrm{A} / \mathrm{Mg}-0$, in which no magnesia was added, presents a very low loss tangent over the 


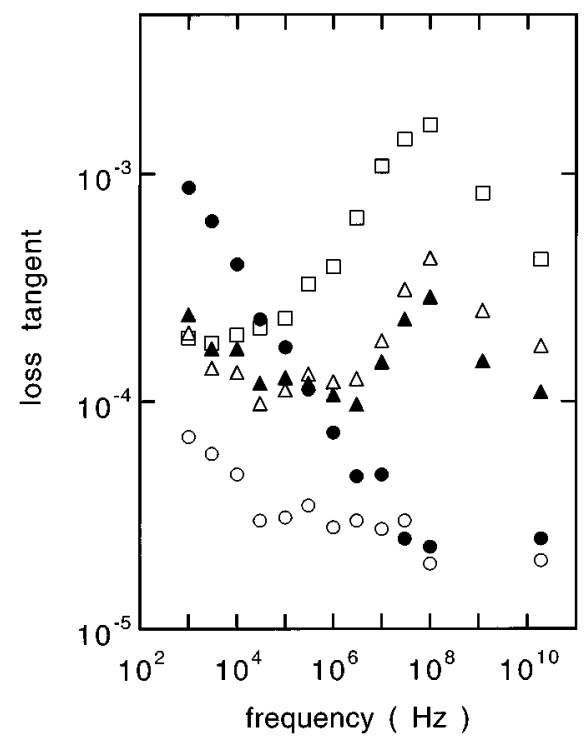

FIG. 2. Frequency dependence of loss tangent for the samples with different contents of magnesia. A/Mg-0 ( $), \mathrm{A} / \mathrm{Mg}-0.05(\square), \mathrm{A} / \mathrm{Mg}-0.1(\triangle), \mathrm{A} / \mathrm{Mg}-$ $0.2(\boldsymbol{\Lambda}), \mathrm{A} / \mathrm{Mg}-1(\bullet)$.

whole frequency range. This behavior is similar to that observed previously ${ }^{1}$ for very high-purity alumina. If a small quantity of $\mathrm{MgO}$ is added to the starting alumina powder, a peak in the loss tangent appears near $100 \mathrm{MHz}$, as observed in Fig. 2 for the sample $\mathrm{A} / \mathrm{Mg}-0.05$. Surprisingly, further increasing the magnesia concentration gives rise to a decrease in the peak height (see curves for samples $\mathrm{A} / \mathrm{Mg}-0.1$ and $\mathrm{A} / \mathrm{Mg}-0.2)$. In fact, the sample $\mathrm{A} / \mathrm{Mg}-1$, whose magnesia content is $1 \%$, does not present such a peak and the loss tangent value at high frequency is comparable to that of the high-purity sample. It is interesting to note that the position and shape of the peak coincides with those found for other commercial alumina samples which also contain $\mathrm{Mg}$ as a main impurity (see samples named BIO and VITOX reported in Ref. 1). Figure 3 summarizes the observed effects showing the measured loss tangent at $100 \mathrm{MHz}$ as a function of magnesia concentration. In Fig. 3 the data for alumina samples

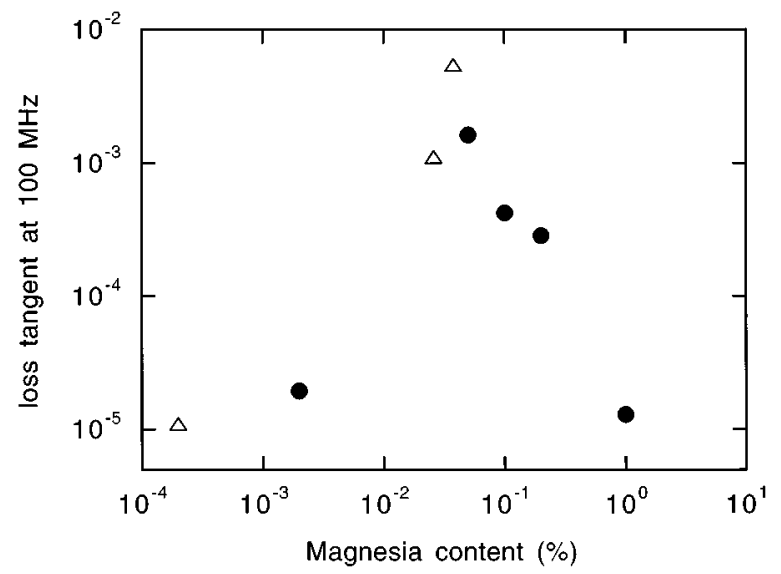

FIG. 3. Loss tangent measured at $100 \mathrm{MHz}$ at room temperature as a function of the magnesia content for the different samples used in this work and in Ref. $1(\triangle)$.

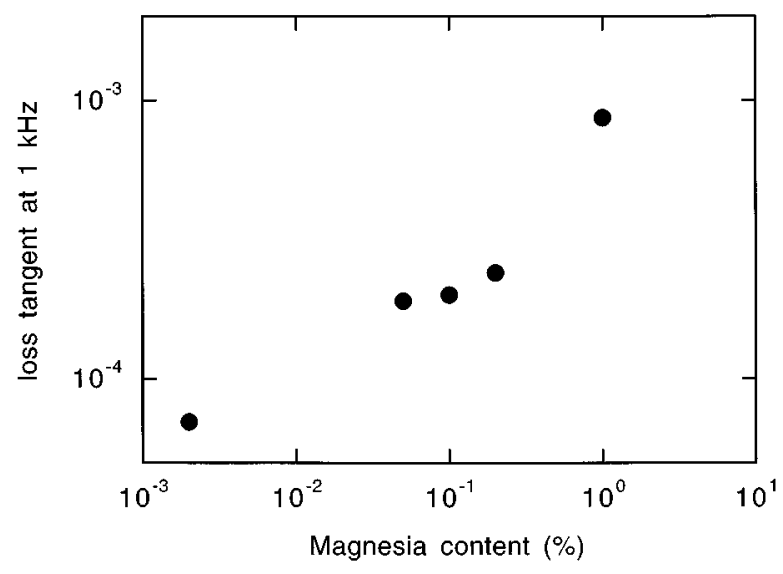

FIG. 4. Loss tangent measured at $1 \mathrm{kHz}$ at room temperature as a function of the magnesia content for the different samples used in this work.

studied in Ref. 1 are also included. On the other hand, in Fig. 2 one observes an increase in loss tangent with increasing magnesia content at low frequency, which must be related with some lower frequency process. Figure 4 shows the measured loss tangent at $1 \mathrm{kHz}$ as a function of magnesia concentration. A clear correlation can be observed within them.

The permittivity values obtained for all the samples at 15 $\mathrm{GHz}$ are given in Table II. The values are near to 10 , in agreement with other data for alumina. ${ }^{1}$ The differences observed between the samples may be associated with the differences in density and hence explained taking into account the permittivity of air considering the sample as a heterogeneous material composed of two different components: an alumina matrix and air bubbles as a second dielectric material. This produces a variation in the permittivity of the material according to the Clausius-Mosotti equation. ${ }^{12}$

In general no frequency dependence of permittivity has been observed. This indicates that the change over all the frequency range is less than 0.03 , the only exception being the $\mathrm{A} / \mathrm{Mg}-0.05$ sample in which a decreasing step in the permittivity is observed at the frequency at which the loss tangent peak appears (see Fig. 5, in which both the permittivity and loss tangent for sample $\mathrm{A} / \mathrm{Mg}-0.05$ are given as a function of frequency). This behavior is as predicted for dipolar

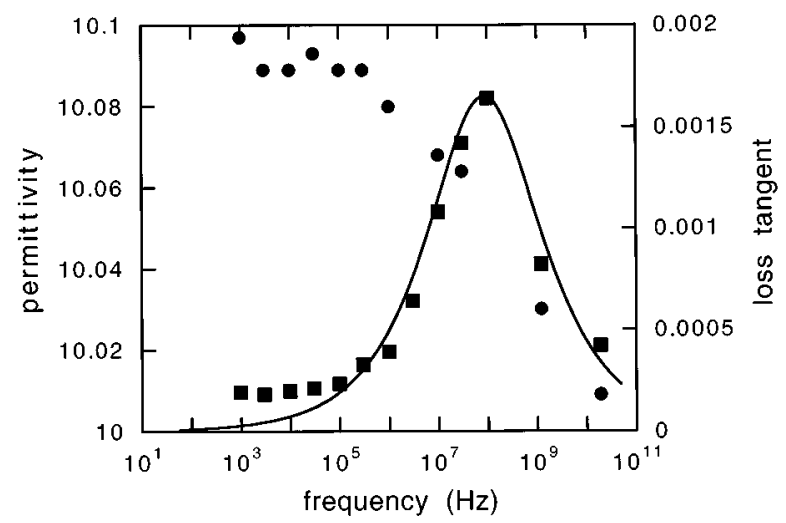

FIG. 5. Frequency dependence of permittivity (O) and loss tangent ( $\mathbf{\square})$ at room temperature for sample type $\mathrm{A} / \mathrm{Mg}-0.05$. 


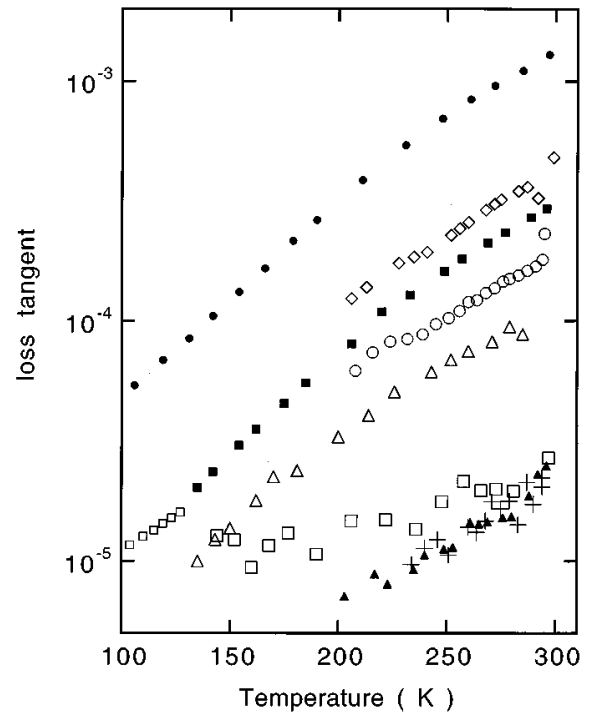

FIG. 6. Temperature dependence of loss tangent at $15 \mathrm{GHz}$ for the different samples used in this work and in Ref. 1. VITOX $(\bullet)$, BIO (ם), CER9999 $(\boldsymbol{\Lambda}), \mathrm{A} / \mathrm{Mg}-0(+), \mathrm{A} / \mathrm{Mg}-0.05(\diamond), \mathrm{A} / \mathrm{Mg}-0.1(\bigcirc), \mathrm{A} / \mathrm{Mg}-0.2(\triangle)$ and $\mathrm{A} / \mathrm{Mg}-1(\square)$.

relaxation processes. In Fig. 5 the solid line represents the equation proposed by Jonscher for nonideal dipolar relaxation in real dielectric materials ${ }^{13}$

$$
\operatorname{tg} \delta \propto \frac{1}{\left(\omega / \omega_{p}\right)^{-m}+\left(\omega / \omega_{p}\right)^{1-n}}
$$

with $m=1-n=0.4$, and $\omega_{p} / 2 \pi=0.9 \times 10^{8} \mathrm{~Hz}$.

The study of the evolution with temperature of these relaxation processes can give information about their characteristics. The available instrumentation does not allow one to measure as a function of temperature at the frequency at which the loss tangent maximum appears, however measuring at $15 \mathrm{GHz}$ it is possible to obtain some valuable information. The data obtained as a function of temperature at 15 $\mathrm{GHz}$ are shown in Fig. 6. Once more different behaviors are obtained depending on the magnesia content. The loss tangent temperature dependence of sample $\mathrm{A} / \mathrm{Mg}-0$ shows a decrease of loss tangent with decreasing temperature and it is similar again to that reported for sample CER9999 in Ref. 1, also shown in Fig. 6. This behavior is related to the interaction of electromagnetic fields with lattice vibrations and hence represents intrinsic losses of the crystal. ${ }^{14}$ The samples with small quantities of $\mathrm{Mg}(0.1 \%, 0.2 \%$, and $0.05 \%)$ also present a decrease of loss tangent with decreasing temperature but with higher absolute values and with a higher slope indicating that the observed behavior is associated with a different origin, probably with the displacement towards lower frequencies of the relaxation peak observed at 100 $\mathrm{MHz}$ at room temperature. This behavior also finds a parallelism with that reported for other samples (BIO and VITOX) in Ref. 1, also shown in Fig. 6. Finally, the loss tangent of the sample $\mathrm{A} / \mathrm{Mg}-1$ with $1 \%$ of magnesia, that does not present such a peak in the loss tangent, has a much weaker temperature dependence. The origin of this behavior may be related well with the contribution of the lattice, as modified by the presence of impurities, or related well with the low-frequency peak whose tail at high frequency is observed in Fig. 2.

In summary, it seems that the presence of magnesia in alumina induces at least two different relaxation processes. One at very high frequencies and the other at low frequencies, but their concentration dependence is completely different. For the low-frequency process, there is a clear increase of loss tangent with magnesia concentration (see Fig. 4). In fact it can be very well fitted to a 0.33 power law, indicating that the defect responsible for this process is distributed uniformly in the volume of the sample and is clearly associated with the magnesia concentration. A good candidate for this defect is the spinel precipitates. ${ }^{9}$

For the high-frequency relaxation process, it is not so easy to understand the dependence of the dielectric properties with magnesia concentration. As shown in Fig. 3, it is clear that there is a maximum loss tangent for a concentration value of about $400 \mathrm{ppm}$. This value is the approximate solubility limit of $\mathrm{Mg}$ in $\mathrm{Al}_{2} \mathrm{O}_{3}$ at the sintering temperature employed $^{15,16}$ and could therefore be related. Usually magnesia is used as a sintering aid in alumina fabrication because it inhibits grain growth, and hence by avoiding large grains produces an increase of densification. These effects are due to an increase in the diffusion coefficient for Al because of the presence of interstitial $\mathrm{Al}^{3+}$ ions. ${ }^{6,7,17}$ These defects result from the substitution of $\mathrm{Al}^{3+}$ by $\mathrm{Mg}^{2+}$ in the lattice. Because of the difference in the valence, the substitutional $\mathrm{Mg}^{2+}$ represents a negative charge with respect to the lattice and therefore acts as a potential hole trap by charge compensation according to the reaction

$$
\left(\mathrm{Mg}^{x}\right)_{\mathrm{Al}} \leftrightarrow\left(\mathrm{Mg}^{\prime}\right)_{\mathrm{Al}}+h^{0},
$$

where the equilibrium constant increases with the temperature. ${ }^{18}$ The used notation is proposed by Kröger and Vink $^{19,20}$ where the subscript indicates the position of the defect in the lattice and the superscript indicates the charge with respect to the lattice. This kind of defect constitutes a dipole, the orientation of which changes according to the different equilibrium positions of the hole relative to the $\mathrm{Mg}^{2+}$. This localized orientational dipole with high mobility due to the low hole mass may be responsible for the relaxation process observed by dielectric spectroscopy at high frequency. Similar effects have been observed in Al-doped quartz, in which the subvalent impurity $\mathrm{Al}^{3+}$ substitutes the $\mathrm{Si}^{4+}$ ion in the $\mathrm{SiO}_{2}$ lattice, also trapping a hole and giving rise to relaxation process centered in the $\mathrm{GHz}$ range associated with the center $\left(\mathrm{Al}^{x}\right)_{\mathrm{Si}} \cdot{ }^{21,22}$ Both systems are quite similar because the ionic radius of the impurity is similar to that of the substitutional ion and the impurity has a lower charge state with a difference to the perfect lattice of +1 .

The following mechanism is proposed to explain the observed loss dependence on the magnesia concentration at high frequencies (see Fig. 3). Below the solubility limit an increase of magnesia concentration implies an increase of dissolved $\mathrm{Mg}$ at the sintering temperature. On cooling down to room temperature a fraction of this $\mathrm{Mg}$ will remain in solution. It is reasonable to expect that under these conditions the higher the initial disolved $\mathrm{Mg}$, the higher the dipole 
concentration and hence a higher dipolar relaxation peak. In the case where the magnesia concentration is over the solubility limit, the disolved $\mathrm{Mg}$ concentration cannot increase, and therefore one may expect an increase of $\mathrm{MgAl}_{2} \mathrm{O}_{4}$ precipitates, or $\mathrm{Mg}$ aggregation. These may act as nucleation centers during cooling, and even produce a decrease of disolved Mg. This would explain the decrease in the height of the loss peak with increasing concentration over $400 \mathrm{ppm}$.

\section{CONCLUSIONS}

The presence of magnesia in $\mathrm{Al}_{2} \mathrm{O}_{3}$ gives rise to an increase of loss tangent over a wide frequency range (1 $\mathrm{kHz}-15 \mathrm{GHz}$ ). The main reasons for this increase are a dipolar relaxation process centered at $10^{8} \mathrm{~Hz}$ whose height is maximum when the $\mathrm{Mg}$ concentration is around $400 \mathrm{ppm}$ and another relaxation process at low frequency $(<1 \mathrm{kHz})$ whose intensity is proportional to the magnesia concentration. A model is proposed to explain the dipolar relaxation and its dependence on $\mathrm{Mg}$ concentration. The effect of $\mathrm{Mg}$ on dielectric absorption is of importance for $\mathrm{rf}$ windows used in the heating and diagnostics systems of fusion machines since a level of about $400 \mathrm{ppm}$ of $\mathrm{Mg}$ may be reached in pure alumina after one year of neutron irradiation at a flux equivalent to $1 \mathrm{MW} / \mathrm{m}^{2}$. This power level is expected for future fusion machines as NET or ITER at the first wall.

\section{ACKNOWLEDGMENTS}

The authors wish to thank Dr. E. R. Hodgson (CIEMAT, Spain) for critical reading of the manuscript. This work has been performed in the framework of the CIEMAT project for nuclear fusion research supported by european communities within the european fusion technology program.

${ }^{1}$ J. Mollá, R. Heidinger, and A. Ibarra, J. Nucl. Mater. 212-215, 1029 (1994).

${ }^{2}$ G. Link and R. Heidinger, in 18th International Conference on Infrared and Millimeter Waves, edited by J. R. Birch and T. J. Parker; Proc. SPIE 2104, 150 (1993).

${ }^{3}$ R. Moreno, P. Miranzo, J. Requena, J. S. Moya, J. Mollá, and A. Ibarra, Ceram. Trans. 21, 225 (1991)

${ }^{4}$ L. H. Rovner and G. R. Hopkins, Nucl. Technol. 29, 274 (1976).

${ }^{5}$ R. L. Coble, J. Appl. Phys. 32, 793 (1961).

${ }^{6}$ M. P. Harmer and R. J. Brook, J. Mater. Sci. 15, 3017 (1980).

${ }^{7}$ S. J. Bennison and M. P. Harmer, J. Am. Ceram. Soc. 68, C22 (1985).

${ }^{8}$ S. J. Bennison and M. P. Harmer, Adv. Ceram. 6, 171 (1983).

${ }^{9}$ W. C. Johnson and D. F. Stein, J. Am. Ceram. Soc. 58, 485 (1975).

${ }^{10}$ A. Kakimoto, A. Etoh, K. Hirano, and S. Nonaka, Rev. Sci. Instrum. 58, 269 (1987).

${ }^{11}$ J. Mollá, A. Ibarra, J. Margineda, J. M. Zamarro, and A. Hernández, IEEE Trans. Instrum. Meas. 42, 817 (1993).

${ }^{12}$ W. R. Tinga, W. A. G. Voss, and D. F. Blossey, J. Appl. Phys. 44, 3897 (1973).

${ }^{13}$ A. K. Jonscher, in Dielectric Relaxation in Solids (Chelsea, London, 1983), Chap. 5.

${ }^{14}$ G. Link and R. Heidinger, in Ref. 2.

${ }^{15}$ J. G. J. Peelen, Materials Science Research, edited by G. C. Kuczynski (Plenum, New York, 1975), Vol. 10, p. 443.

${ }^{16}$ S. K. Roy and R. L. Coble, J. Am. Ceram. Soc. 51, 1 (1968).

${ }^{17}$ R. L. Coble, H. Song, R. J. Brook, C. A. Handwerker, and J. M. Dynys, Adv. Ceram. 10, 839 (1984).

${ }^{18}$ H. W. Wang, C. H. Lee, F. A. Kröger, and R. T. Cox, Phys. Rev. B 27, 3821 (1983).

${ }^{19}$ F. A. Kröger and H. J. Vink, Solid State Physics, edited by F. Seitz, and D. Turnbull (Academic, New York, 1956), Vol. 3, p. 307.

${ }^{20}$ F. A. Kröger, The Chemistry of Imperfect Crystals (North-Holland, Amsterdam, 1974), Vol. 2, p. 14.

${ }^{21}$ N. W. Ashcroft and N. D. Mermin, Solid State Physics (Holt-Saunders, Tokyo, 1976), Chap. 27.

${ }^{22}$ O. F. Schirmer, Solid State Commun. 18, 1349 (1976). 